\title{
Void Formation and Breaking in a Packed Bed
}

\author{
G.S.S.R.K. SASTRY, G.S. GUPTA and A.K. LAHIRI \\ Department of Metallurgy, Indian Institute of Science, Bangalore -560 012, India. E-mail: govind@metalrg.iisc.ernet.in
}

(Received on May 22, 2002; accepted in final form on September 27, 2002)

\begin{abstract}
An experimental study has been carried out to understand the void formation and breaking in a packed bed using two-dimensional glass models. No experimental data are available in the literature on void initiation and breaking which is essential to understand the aerodynamics of the packed bed reactors such as blast furnace, catalytic reformer and solid drying process. The effect of particle size, density, gas flow rate, bed height and model width on the formation of void and its breaking has been studied in detail. The effect of frictional properties of the particulate material on the void formation and breaking has also been studied using modified Janssen's equation. Pressure and velocity measurements have been taken using manometers and a hot wire anemometer to understand the void formation and breaking phenomena. Correlations have been proposed to predict the void formation and void breaking.
\end{abstract}

KEY WORDS: void formation; void breaking; pressure and velocity measurement; raceway; void correlations.

\section{Introduction}

Packed beds are used in many chemical and metallurgical applications such as catalytic reformer, solid drying, blast furnaces and COREX process. In catalytic reformer, which is used for the removal of coke deposits from catalyst, the reaction gas is blown across the bed for reactivation and the reactivated catalyst sent back to the reactor. There is an upper bound on the flow of reaction gas imposed by the phenomenon of 'pinning'. When pinning occurs, solids flow through the bed ceases. ${ }^{1)}$ Similarly, the cross flow of gas occurs in the lower parts of the blast furnace where gases are injected from the tuyere in to the coke bed. In order to understand the aerodynamics of these systems one has to know the conditions at which void formation and breaking occurs so that the phenomena like pinning can be explained and can be avoided.

Doyle III et $a l_{.}{ }^{2)}$ have studied beds of cross flow theoretically in order to study the pinning effect in catalytic reformer. Their analysis is based on force balance approach considering the gas drag, stresses and gravity forces. This analysis permits the determination of the gas cross flow rate at which solid flow ceases in moving beds. They had also mentioned the condition at which initiation of void formation will take place, however, they did not report any theoretical or experimental data. The simplified model, which they had presented, is based on arbitrary assumption of the radial variation of the stress in the moving beds. Due to this reason their numerical values are greater than the experimental values. They did not give any experimental values for void formation and breaking. The analysis was confined to the growth of void till the solid flow ceases in moving bed. Xu et al., ${ }^{3)}$ using Discrete Element Method and Computational Fluid Dynamics approach, have done a theoretical study of void formation to fluidizations in a packed bed. However, the applicability of their theoretical results is questionable as the size of the particle and opening (width) of the bed is same which can not give the true fluidisation. No experimental results were shown to compare their theoretical predictions.

Void formation and breaking is an important phenomena in all packed bed process including blast furnace. In the blast furnace, this phenomenon has been studied in terms of raceway. When a high velocity of gas is introduced into a packed bed through a tube, a cavity is formed in front of the tube nose. This cavity, in the ironmaking blast furnace, is formed in front of the hot blast tuyere and is known as the raceway. The size and shape of the raceway affects the flow of gases and liquid metal/slag in the lower part of the blast furnace. ${ }^{4,5)}$ Many correlations have been put forward to predict the raceway size based on both theoretical ${ }^{6,7)}$ and experimental $^{8-11)}$ results. It is observed that all the study until now has been concentrated on characterizing the size of the raceway in terms of the blast parameters, material properties and system dimensions.

Surprisingly even in raceway literature, to the best of authors knowledge, nobody has studied experimentally the condition at which void initiation and breaking occurs. Void formation and breaking are important phenomena in any packed bed process which may describe the stability conditions of these processes. It has been reported ${ }^{12)}$ that as the raceway size increases productivity of the blast furnace also increases. However, the increase in raceway size can be achieved to a certain limit after which raceway may become unstable and thus the operation of the blast furnace. Therefore, this study (raceway breaking) may also help to understand this phenomenon.

Therefore, in the present study an attempt has been made to understand the void formation and breaking phenomena in a packed bed experimentally. This study will help funda- 


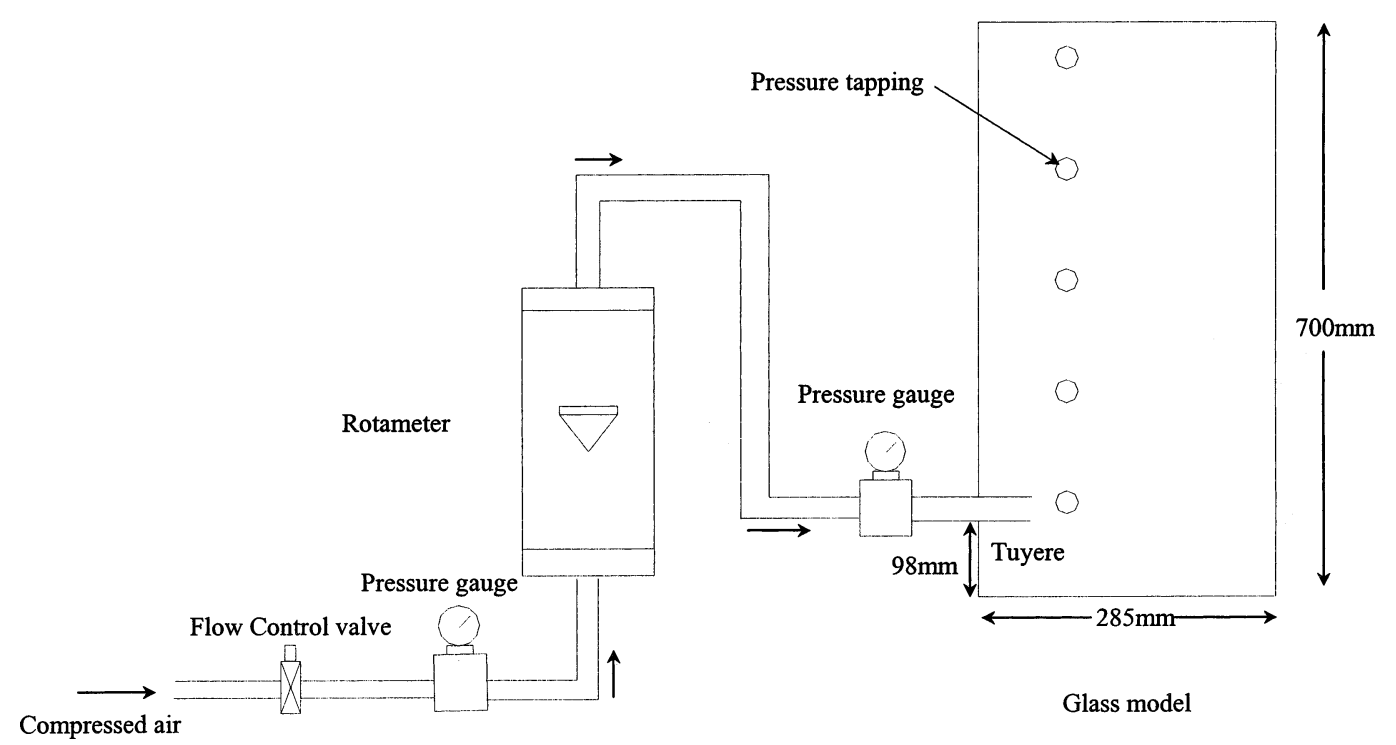

Fig. 1. Schematic diagram of experimental setup.

mentally to understand the packed bed reactors further. The effect of various parameters such as bed height, particle size and density and model width on void formation and breaking has also been studied.

\section{Material and Methods}

\subsection{Experimental Setup}

Experiments were performed using two-dimensional models. A schematic of the experimental setup is shown in Fig. 1. The sidewalls of the models are made of glass. It must be mentioned ${ }^{13)}$ here that the perspex model has a tendency to bulge upon loading and a slight inward curvature develops in the model with time which is undesirable. Therefore, the reproducibility of the results in perspex model deteriorates with time. However, reproducibility can be increased using thicker perspex sheet and reinforcing the model. In the present study, only glass models were used. The tuyere in the form of a rectangular slot was placed horizontally $98 \mathrm{~mm}$ above the base of the model. In order to measure the pressure, using water and mercury manometers, $6 \mathrm{~mm}$ diameter holes were drilled at a distance of 65 $\mathrm{mm}$ from the tuyere-side wall at heights of $100 \mathrm{~mm}, 200$ $\mathrm{mm}, 300 \mathrm{~mm}, 400 \mathrm{~mm}$, and $500 \mathrm{~mm}$ from the base of the model.

Compressed air was introduced into the model through a flow control valve, two pressure gauges, and a rotameter which were connected in series. The pressure gauges measure the pressure of the air just before it enters the rotameter and the tuyere.

\subsection{Experimental Conditions}

All the models were $700 \mathrm{~mm}$ in height and $285 \mathrm{~mm}$ in breadth. The experiments were performed using six model widths ranging from 8 to $20 \mathrm{~mm}(8,10,13,15,17$ and 20 $\mathrm{mm}$ ). The properties of the solid materials (quartz and polypropylene) used as packing are given in Table 1. The bed heights were varied from 100 to $400 \mathrm{~mm}$ in steps of $100 \mathrm{~mm}$ depending upon the requirement. For conducting two-dimensional experiments, tuyere slot heights of $5 \mathrm{~mm}$
Table 1. Properties of solids used.

\begin{tabular}{|c|c|c|c|c|c|}
\hline Material & Shape & $\begin{array}{c}\text { Density } \\
\left(\mathrm{kg} / \mathrm{m}^{3}\right)\end{array}$ & $\begin{array}{c}\text { Size Range } \\
\text { BSS Mesh Nos. }\end{array}$ & $\begin{array}{c}\text { Void } \\
\text { Fraction }\end{array}$ & $\begin{array}{c}\text { Equivalent } \\
\text { Diameter, } \mathrm{mm} \\
\text { Average }\end{array}$ \\
\hline & & -10 to +12 & & 1.55 \\
Quartz & Irregular & 2550 & -12 to +14 & & 1.29 \\
& & -14 to +16 & 0.4 & 1.09 \\
& & -16 to +18 & & 0.925 \\
& & & -20 to +25 & & 0.655 \\
\hline \multirow{5}{*}{ Polypropylene } & Spherical & \multirow{2}{*}{910} & -6 to +7 & & 3.1 \\
& & & -8 to +10 & & 2.6 \\
& & & -10 to +14 & 0.48 & 1.84 \\
& & & -12 to +16 & & 1.44 \\
& & & -16 to +25 & & 0.80 \\
\hline
\end{tabular}

and $6 \mathrm{~mm}$ were considered. All the experiments were carried out with horizontal tuyeres. The indicated flow rate was varied from $0.3 \times 10^{-3}$ to $2 \times 10^{-3} \mathrm{~m}^{3} / \mathrm{s}$, corresponding to the exit blast velocities from the tuyere of 4 to $25 \mathrm{~m} / \mathrm{s}$. The pressure of the air entering the rotameter varied from about 1.0 to $2.0 \mathrm{~atm}$. All the experiments were carried out at room temperature. Experiments were conducted with various particles size as shown in Table 1. In a few experiments, the gas velocity measurements were made at the top of the bed using a hot wire anemometer.

\subsection{Experimental Procedure}

The model was first filled up to the required bed height from the top and then air was blown through the tuyere in the range of $0.6-1.3 \times 10^{-3} \mathrm{~m}^{3} / \mathrm{s}$ for about $1 \mathrm{~min}$ and then stopped. The entire bed and the top surface were disturbed due to the air flow. The top surface was then made horizontal and it was found that the bed height had reduced, thereby indicating that the bed voidage had decreased. More material was added into the model so that the bed height was up to the required level and the above procedure was repeated three to five times depending on whether the bed height was undergoing any change due to blowing of air. This ensured the further change in voidage did not occur during the experiments. For each bed height, the trace of the top surface was taken before and after the experiment.

Once the model was filled up to the required bed height, 


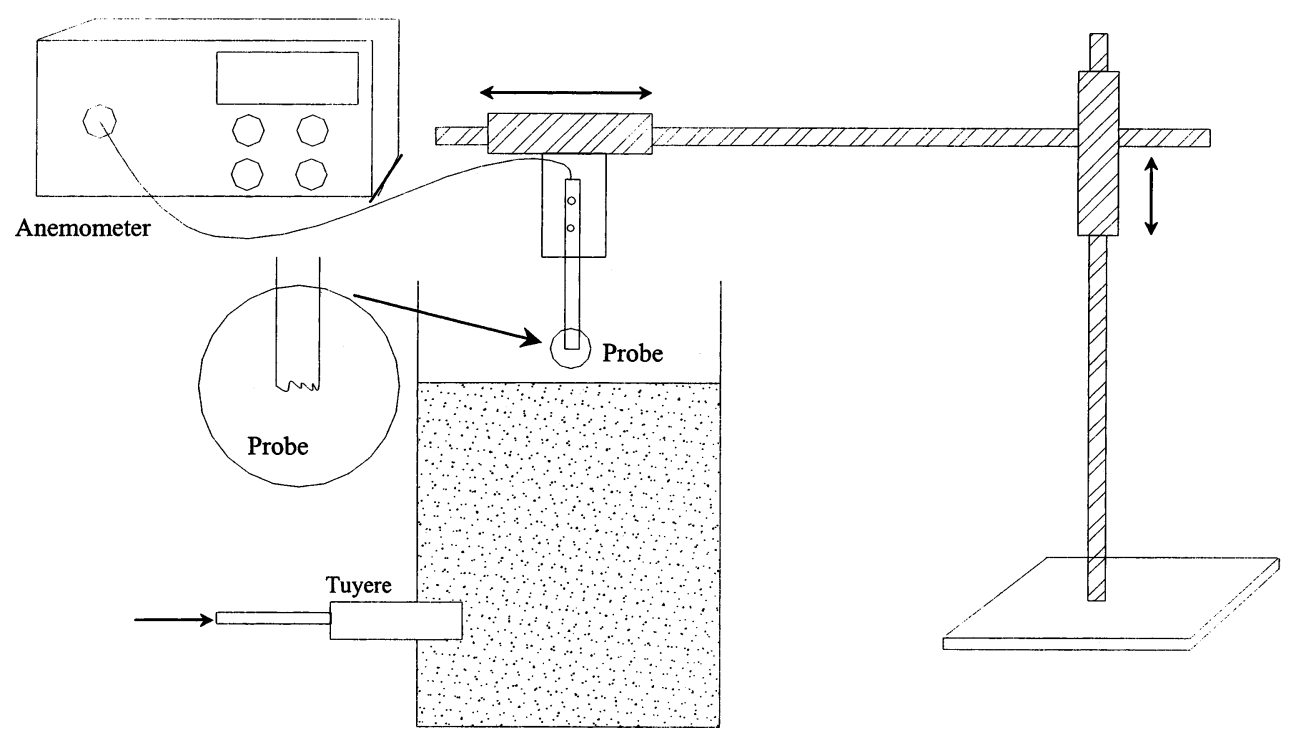

Fig. 2. Schematic of velocity measurement using hot wire anemometer.

the flow of air was gradually increased, in such a manner that a small void (cavity) formed in front of the tuyere. During the experiments, readings of the rotameter, pressure gauges and manometers were noted down at regular intervals.

On further increase in air flow, particles became unstable and started moving along the boundary of the already formed void, in a circular motion forming a small raceway. These conditions were taken as the raceway formation conditions which are well documented in the literature. After this, as the flow of air was gradually increased, the raceway expanded in all directions. At a desired gas flow rate, the raceway was allowed to stabilize for about $2 \mathrm{~min}$. The traces of raceway on the side wall of the model were taken using the tracing paper. Then, the flow of air was gradually increased till breaking of the raceway/void occurred. Under the breaking condition, fluctuation in the pressure was observed which was due to periodical contraction and expansion/breaking of the cavity. ${ }^{3)}$ Therefore, manometers readings were noted down every $15 \mathrm{~s}$ for about two to $3 \mathrm{~min}$. After that, the flow of air was decreased to zero. Another set of readings was taken replicating the entire set of experimental conditions used. The averages of these two were taken as the observed values. The same procedure was repeated for packing materials of different density and size.

The actual voidage in the bed, after the each experiment, was calculated by weighing the entire contents of the bed and also measuring the volume of material in the bed.

\subsection{Velocity Measurements}

The velocity of the gas, exiting from the top of the bed was measured with the help of hot wire anemometer. Experiments were conducted with $3.1 \mathrm{~mm}$ diameter polypropylene particles as the packing material. The velocity profile of the exit gas stream was measured by a hot wire probe, located about $1 \mathrm{~cm}$ above the surface of the bed and at the center of the model width. The probe was connected to the hot wire anemometer as shown in the Fig. 2. Measurements were taken for each $1 \mathrm{~cm}$ distance along the breadth of the bed. The gas flow rate was varied from zero to $1.4 \times 10^{-3} \mathrm{~m}^{3} / \mathrm{s}$.
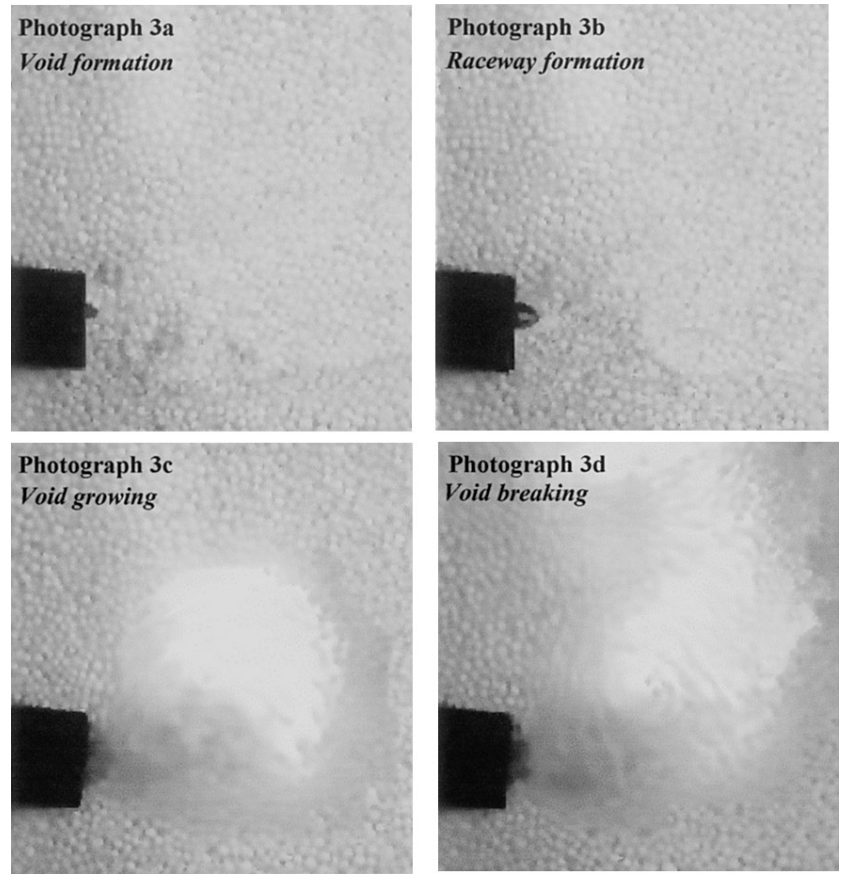

Fig. 3. Photographs showing various stages of raceway at different gas flow rates.

\section{General Observations}

In Fig. 3, four photographs of the bed are shown. In these photographs, four zones can be seen. Initially, in the absence of gas flow, the particles are in static equilibrium. When the momentum of the initial blast is sufficiently high, it disturbs the static equilibrium condition of the particles in front of the tuyere and a small void is formed by displacing the particles from their equilibrium condition as shown in photograph 3a. In the present study, displacement of about two particles diameter in front of the tuyere is taken as void formation. No rotational movement of the particles takes place at this stage. As the blast velocity is increased, at a particular point, it disturbs the conditions which prevailed in the void formation. Particles become unstable and start moving along the void boundary in a circular motion form- 


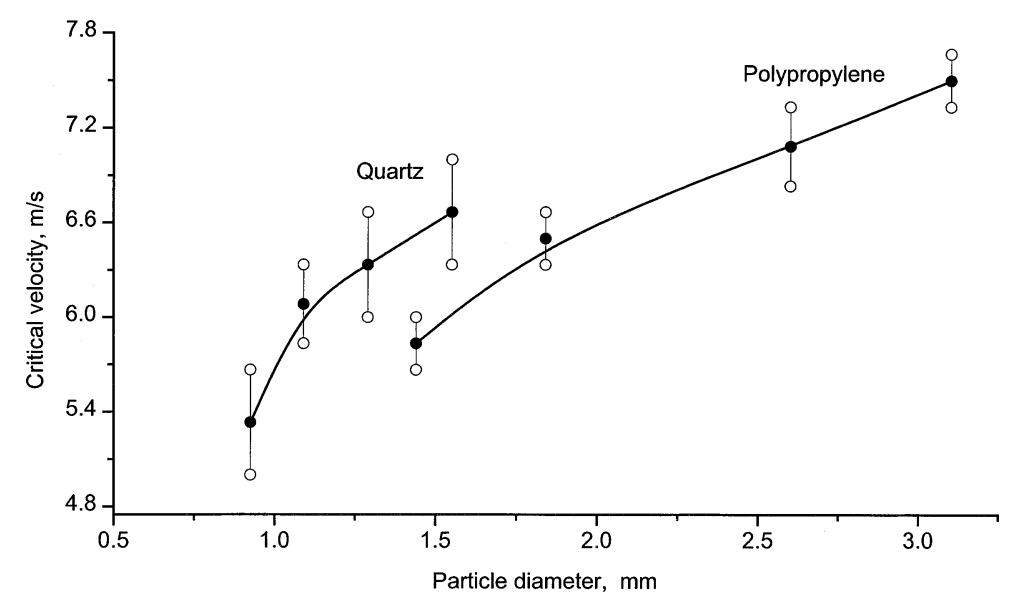

Fig. 4. Critical velocity required for void formation as a function of particle diameter. $W=20 \mathrm{~mm}, H=400 \mathrm{~mm}$ and $d_{\mathrm{t}}=5 \mathrm{~mm}$.

ing a small raceway as shown in photograph $3 \mathrm{~b}$. As the velocity is increased further, the raceway expands in all directions. This condition is shown in photograph $3 \mathrm{c}$. The shape of the raceway is elliptical in form. The cavity remains stable and continuous in shape until it reaches the critical breaking velocity. The breaking condition of void is shown in fourth photograph $3 \mathrm{~d}$. Beyond the critical breaking velocity, the roof of void became unstable and subsequently it collapsed. During this condition, gas bubbles were also seen to travel along the bed height.

\section{Results and Discussion}

Figure 4 shows the effect of the particle diameter on the critical velocity required for formation of the void for quartz and polypropylene. The velocity at which the displacement of about two particles diameter in front of the tuyere occurred has been defined as critical void formation velocity, $V_{\mathrm{vf}}$. It can be seen from the figure that as the particle diameter increases the critical velocity required for forming the void also increases. The larger particle has more mass, therefore, they need more gas velocity. Due to large density difference of more than three times, quartz requires high velocity for void formation for the same particle diameter in comparison to polypropylene as shown in the figure.

Figure 5 shows the effect of the bed height on critical velocity required for the formation of the void. It can be seen as the bed height increases the critical velocity required for the formation of the void also increases and beyond $350 \mathrm{~mm}$ it becomes constant. The bed height beyond which it does not affect the void formation is defined as the effective bed height $\left(H_{\text {eff }}\right)$. In a similar way, the effective bed height can be defined for the raceway formation and void breaking. This behaviour is similar to the raceway behaviour observed by other researchers ${ }^{7)}$ where the raceway diameter becomes independent of bed height beyond $300 \mathrm{~mm}$. They ${ }^{7)}$ used polystyrene as packing material and bed dimensions were $1.2 \times 0.4 \times 0.1 \mathrm{~m}$. It should be noted that Gupta et al. ${ }^{14)}$ did not find any effective bed height during their raceway experiments using polyethylene beads ( $4.1 \mathrm{~mm}$ in diameter) as packed bed material. The dimensions of their apparatus were $2.2 \times 1 \times 0.1 \mathrm{~m}$ and the bed

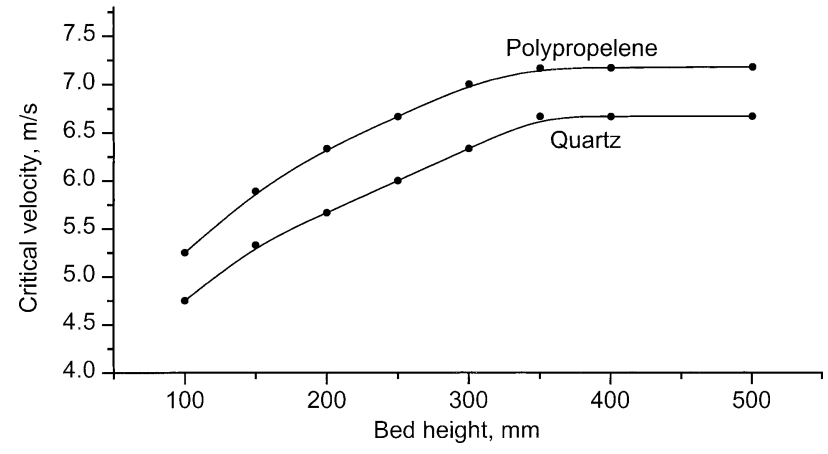

Fig. 5. Critical velocity required for void formation as a function of bed height. $W=20 \mathrm{~mm}, d_{\mathrm{p}}=1.55 \mathrm{~mm}$ (quartz), $d_{\mathrm{p}}=2.6$ mm (polypropylene).

height above the tuyere level during the experiment was up to $1 \mathrm{~m}$. Therefore, the effective bed height is dependent on the dimension of the apparatus and the bulk properties of material. The same conclusion can be drawn based on the classical Janssen's equation ${ }^{15)}$ which gives the normal stress acting on the base of a circular bed of the granular material.

For the present experimental conditions this equation is not applicable as the model is in the shape of rectangular cross section. For the present experimental conditions the expression is ${ }^{16)}$

$$
\sigma_{\mathrm{zz}}=\frac{\gamma}{\left(\left(\frac{2}{w}\right)+\left(\frac{2}{l}\right)\right) K \mu_{\mathrm{w}}}\left[1-\exp \left(-\left(\frac{2}{w}+\frac{2}{l}\right) K \mu_{\mathrm{w}} Z\right)\right]
$$

where $\sigma_{\mathrm{zz}}=$ normal stress on the base; $\gamma=$ bulk density of the material; $\mu_{\mathrm{w}}=$ coefficient of wall friction; $K=$ Janssen's constant, is the ratio of horizontal to vertical principal stresses $=(1-\sin \phi) /(1+\sin \phi), \phi=$ angle of internal friction; $Z=$ height above the base; $w=$ width of the model and $l=$ breadth of the model.

The above equation is applicable in absence of gas flow through a particulate bed. However, in the present studies, flow of gas takes place in the packed bed. So, the experiments were carried out, using gas as the medium, for finding out the coefficient of wall friction between glass and quartz \& glass and polypropylene. Also internal angle of 
friction were measured in presence of gas. It is found that the wall friction coefficients between the glass and quartz and glass and polypropylene are less in presence of gas flow. Similarly, the value of internal angle of friction was less in presence of gas for both the materials. We believe that gas medium is acting as a lubricant between the glass and particles and between the particle-particle. All these experiments were done using shear box apparatus. ${ }^{17)}$

Figure 6 shows the effect of bed height on the pressure exerted by the solid at the base of the model in the presence and absence of the gas flow using the above mentioned equation. It is clear from the figure that the normal stress on the base increases continuously up to a bed height of 300 $\mathrm{mm}$ in presence of the gas flow and then remains constant. So the critical velocity for the void (and similarly for the raceway) formation becomes independent of the bed height. In absence of the gas, the normal stress on base increases up to the bed height of $450 \mathrm{~mm}$ and then remains constant. From Eq. (1) it is clear that normal stress and hence the bed height depend upon system dimensions, wall friction coefficient and internal angle of friction of the material.

Figure 7 shows the variation in the critical velocity required for formation of the void with respect to the change in model width. As the bed width increases from 10 to 20 $\mathrm{mm}$, the critical velocity required for formation of the void

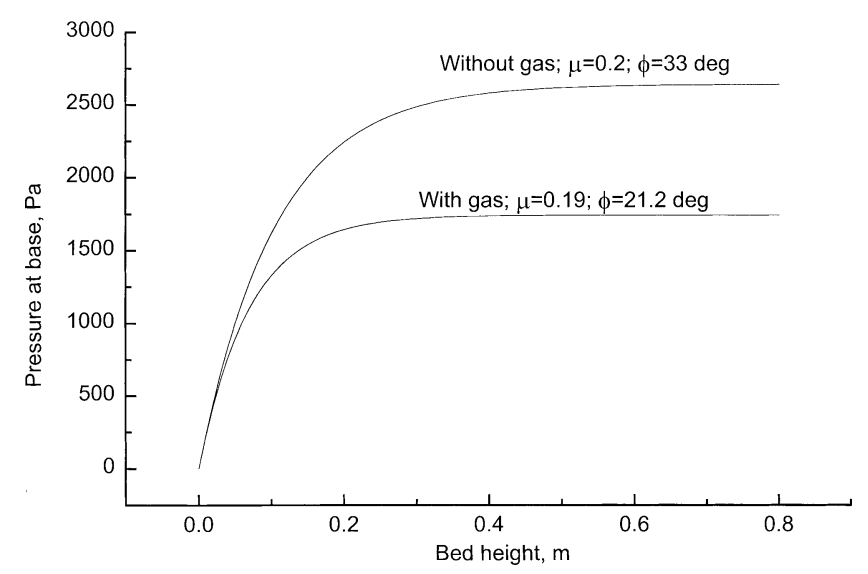

Fig. 6. Effect of bed height on pressure at the base of the glass model using Janssen's equation for quartz particles (with and without air). decreases monotonically. At the critical velocity, the jet impact makes the particles in front of the tuyere to move away from their original positions forming a void. This movement can be of two types, rotational or change of orientation and displacement which leads to the compaction of particles. Obviously, later is dependent on the availability of vacant space in the adjacent volume. As the model width increases, the compaction of particles around the jet becomes easier and thereby void formation takes place at a lower critical velocity.

It is interesting to note that although density of quartz is higher than that of polypropylene, Fig. 7 shows that the critical velocity for void formation is higher for polypropylene compared to that of quartz. This is due to the fact that critical velocity was defined as the velocity at which two particles displacement occurred in front of the tuyere. The particle size of quartz was $1.55 \mathrm{~mm}$ compared to $2.6 \mathrm{~mm}$ for polypropylene. Therefore, at critical velocity, the void size for quartz was smaller by a factor of about 1.7. However, if the particle size is same for both the materials then higher critical velocity is required for void formation for heavier particle as is apparent from Fig. 4.

Figure 8 shows the effect of the particle diameter on critical velocity required for the formation of raceway. This is the condition after void has formed as explained before. In this region, particles are rotating in a circular form. The velocity at which particles rotate in a circular motion forming a full fledged raceway has been defined as critical raceway formation velocity, $V_{\text {rf }}$. Here also, as the particle diameter increases, the critical flow required for formation of the raceway increases. Regarding formation of raceway and its size and shape, abundant literature is available under various conditions. ${ }^{5-10,19,20)}$ Therefore, it is not discussed here.

Figure 9 shows the variation in critical velocity required for breaking the raceway with respect to change in particle diameter. As the particle diameter increases, the critical velocity required for breaking the raceway increases for both quartz and polypropylene particles. Because the density of quartz is almost three times than that of polypropylene, when one compares for the same particle diameter, quartz requires higher velocity for breaking the raceway. The velocity, at which raceway breaks, is defined as critical velocity for raceway breaking, $V_{\mathrm{rb}}$. This breaking of raceway phe-

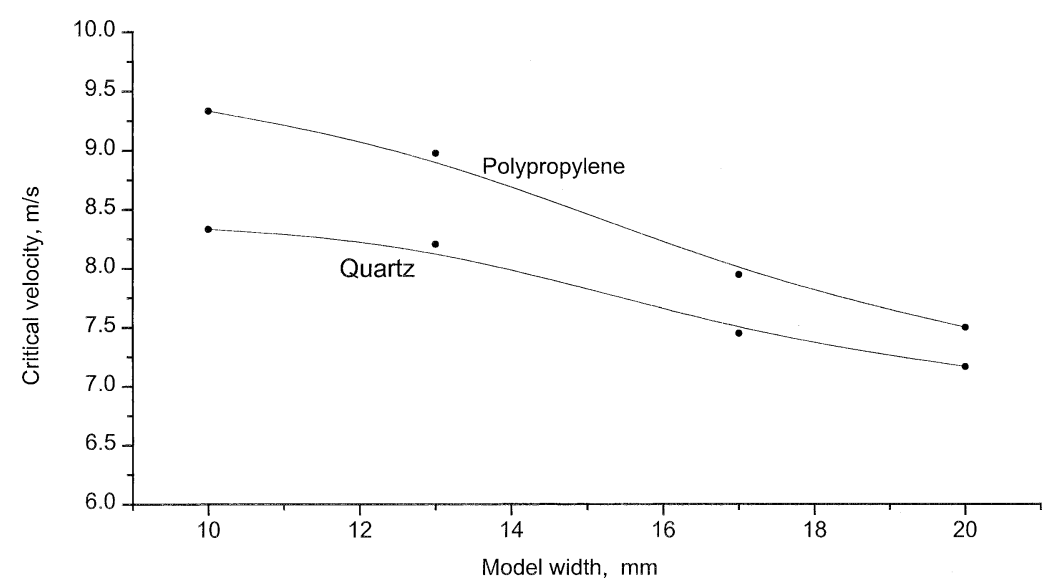

Fig. 7. Critical velocity required for void formation as a function of model width. $H=400 \mathrm{~mm}, d_{\mathrm{p}}=1.55 \mathrm{~mm}$ (quartz) and $d_{\mathrm{p}}=1.84 \mathrm{~mm}$ (polypropylene). 


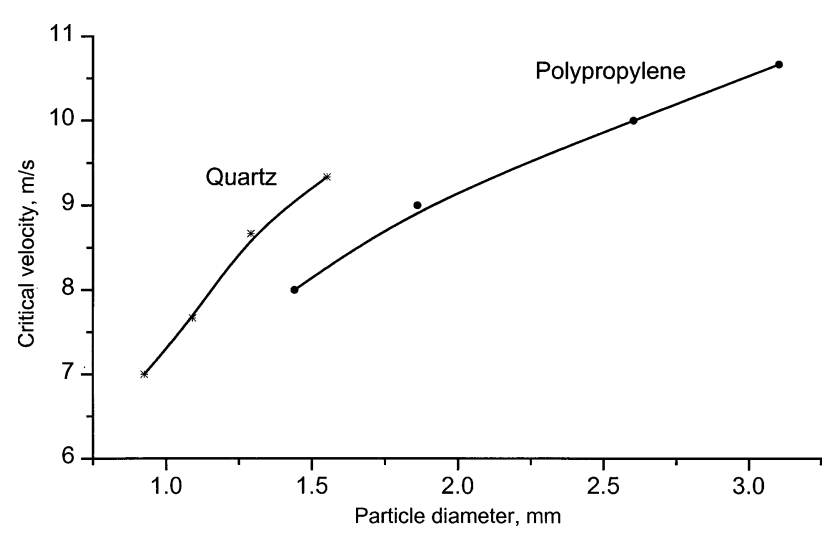

Fig. 8. Critical velocity required for formation of raceway as a function of particle diameter. $W=20 \mathrm{~mm}, H=400 \mathrm{~mm}$, and $d_{\mathrm{t}}=5 \mathrm{~mm}$.

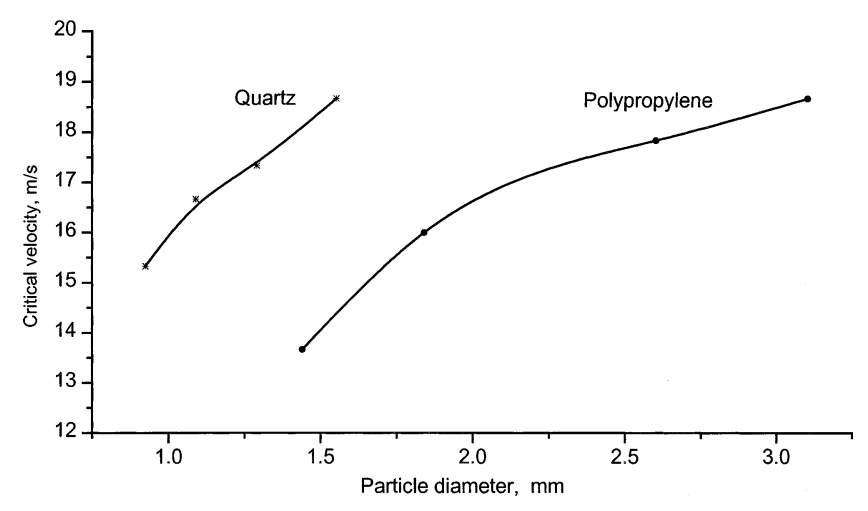

Fig. 9. Critical velocity required for breaking of the raceway as a function of particle diameter. $W=20 \mathrm{~mm}, H=400 \mathrm{~mm}$, $d_{\mathrm{p}}=1.55 \mathrm{~mm}$ (quartz) and $d_{\mathrm{p}}=2.6 \mathrm{~mm}$ (polypropylene).

nomena is very similar to the void formation in fluidization. $^{21)}$ According to this the wall of solids near the base of the raceway represents the weakest region of interface because the void is pressured from all sides as though surrounded by a fluid. Finally this leads to the gas bubbling in the packed bed. During the experiment bubble formation was seen in the bed.

The effect of model width on the breaking of the cavity/void is shown in Fig. 10 for quartz and polypropylene particles. This figure shows that critical velocity required to break the void decreases monotonically with model width which is due to the particle reorientation and displacement as explained in Fig. 7. It is interesting to note that in this case quartz requires more critical velocity than polypropylene to break the void. This is due to the fact that quartz is almost three times heavier than polypropylene and considering the force balance at the top of the void roof, the weight supported by the roof is much more (for the same bed height) compared to polypropylene and thus the higher critical velocity is required to break the void.

Figure 11 shows the variation in pressure drop across the bed with increase in flow rate starting from void formation and up to breaking of the void. As the flow rate is increased the pressure drop across the outlet of the tuyere and pressure inside the raceway, increases continuously. Inset figure clearly shows a distinct increment in pressure drop when void has formed and the second inset shows the pressure drop in void breaking condition. The pressure drop decreas-

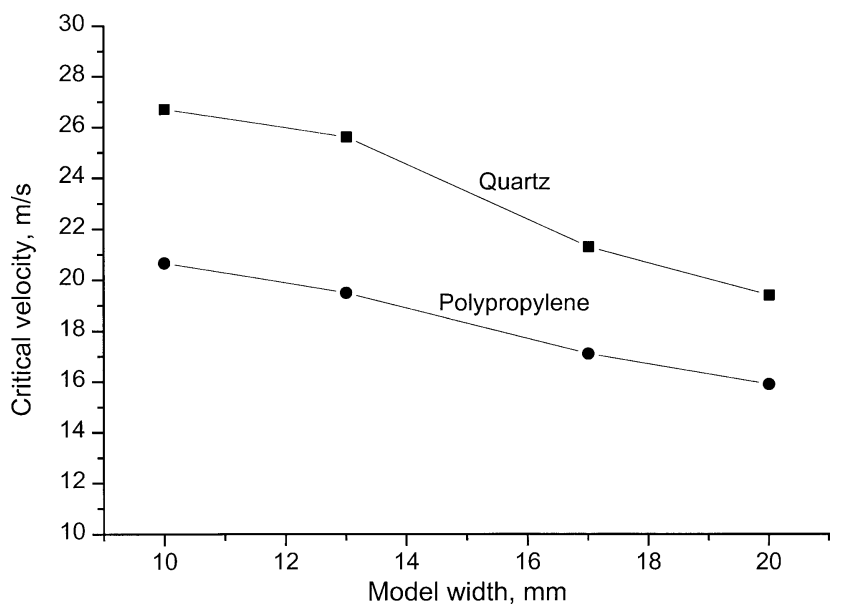

Fig. 10. Critical velocity required for breaking the void as a function of model width. $d_{\mathrm{p}}=1.55 \mathrm{~mm}$ (quartz), $d_{\mathrm{p}}=$ $1.84 \mathrm{~mm}$ (polypropylene), $H=400 \mathrm{~mm}$.

es continuously as the gas flows through the top of the broken void due to collapsing of the roof.

Figure 12 shows the variations in the velocity fields in the presence of raceway along the bed breadth. It can be observed that the velocity leaving from top of the bed is more on top of the raceway compared to the other part of the bed. Peak velocity was observed near the right wall of the model (opposite to the tuyere). It is due to the fact that near the wall the voidage is almost unity, whereas the voidage in the other part of the bed of a randomly packed materials of uniform spheres is usually around 0.48 . Since the circular particles have only point contact with the wall, the voidage at the wall must be nearly unity. Benenati and Brosillow ${ }^{18)}$ also reported the same observation in their formulations. The velocity profiles are comparable to Szekely and Poveromo $^{6)}$ who had also measured them in their two dimensional model. In our study, the fluctuation in the velocity is more as compared to Szekely and Poveromo. This is due to that in our case the bed height from the tuyere level was $200 \mathrm{~mm}$ while in their case the bed was fully packed up to the top however, they did not mention the bed height.

\section{Correlations Obtained from Dimensional Analysis}

Consider the present system of packed bed in which gas is blown laterally into a bed of solids creating a cavity. The momentum of the jet would influence the cavity formation and thus introduces the jet velocity, density of the fluid and the opening of the tuyere. For the stability of the cavity, particle diameter, the solid density and acceleration due to gravity is needed. Therefore, correlations have been obtained between the blast velocity and the other bed parameters using Buckingham Pi theorem. The functional form of the statement is

$$
V_{\mathrm{b}}=f\left(\rho_{\mathrm{g}}, \rho_{\mathrm{s}}, d_{\mathrm{t}}, d_{\mathrm{p}}, H_{\text {eff }}, g\right)
$$

This can be expressed as

$$
\frac{V_{\mathrm{b}}^{2}}{g d_{\mathrm{t}}}=D\left(\frac{\rho_{\mathrm{s}}}{\rho_{\mathrm{g}}}\right)^{A}\left(\frac{H_{\mathrm{eff}}}{d_{\mathrm{t}}}\right)^{B}\left(\frac{d_{\mathrm{p}}}{d_{\mathrm{t}}}\right)^{C}
$$

where, $V_{\mathrm{b}}$ is the blast velocity in $\mathrm{m} / \mathrm{s}, d_{\mathrm{t}}$ is the tuyere open- 


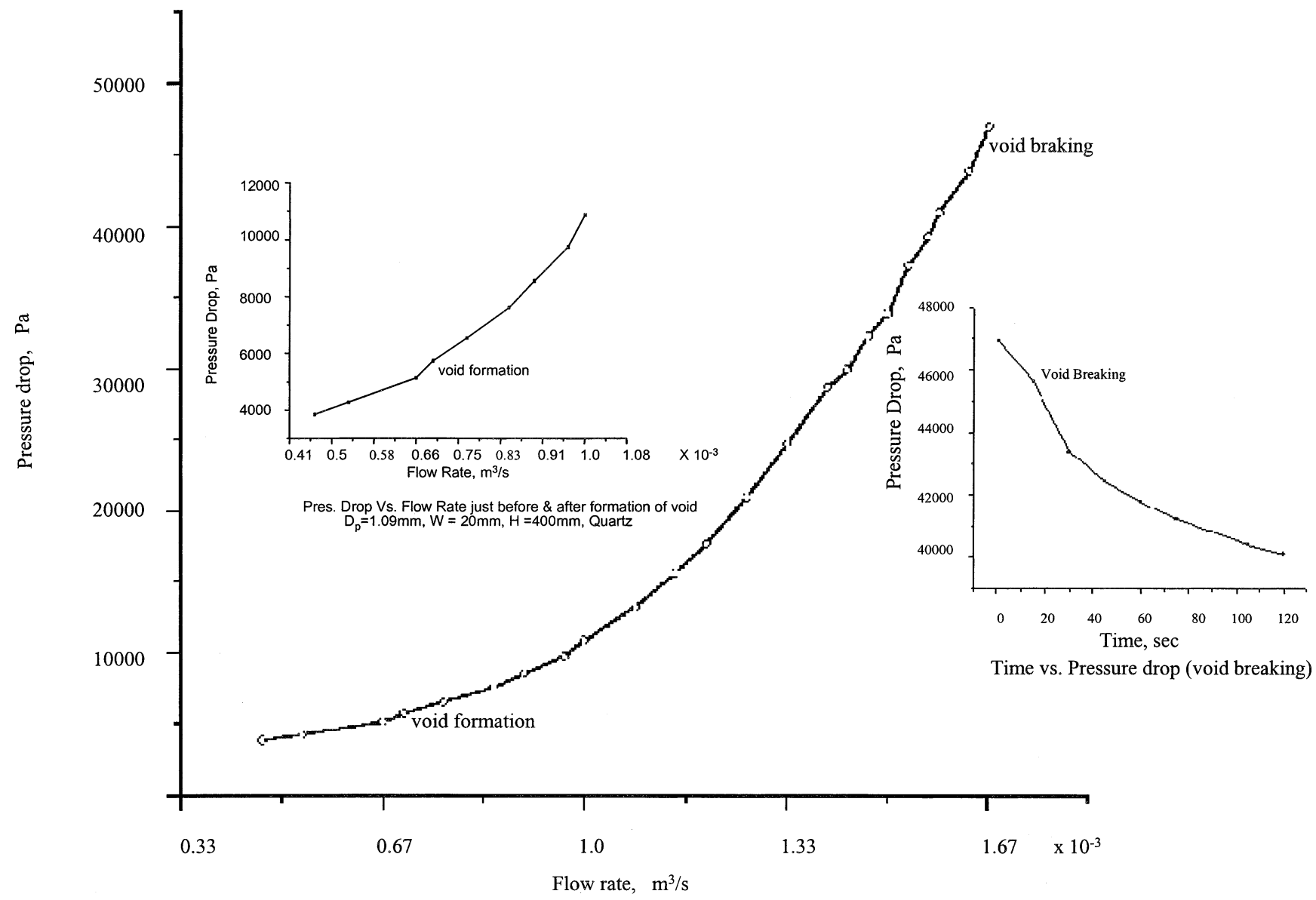

Fig. 11. Pressure drop $v s$. gas flow rate from void formation to raceway breaking. $d_{\mathrm{p}}=1.09 \mathrm{~mm}$ (quartz), $W=20 \mathrm{~mm}$, $H=400 \mathrm{~mm}$.

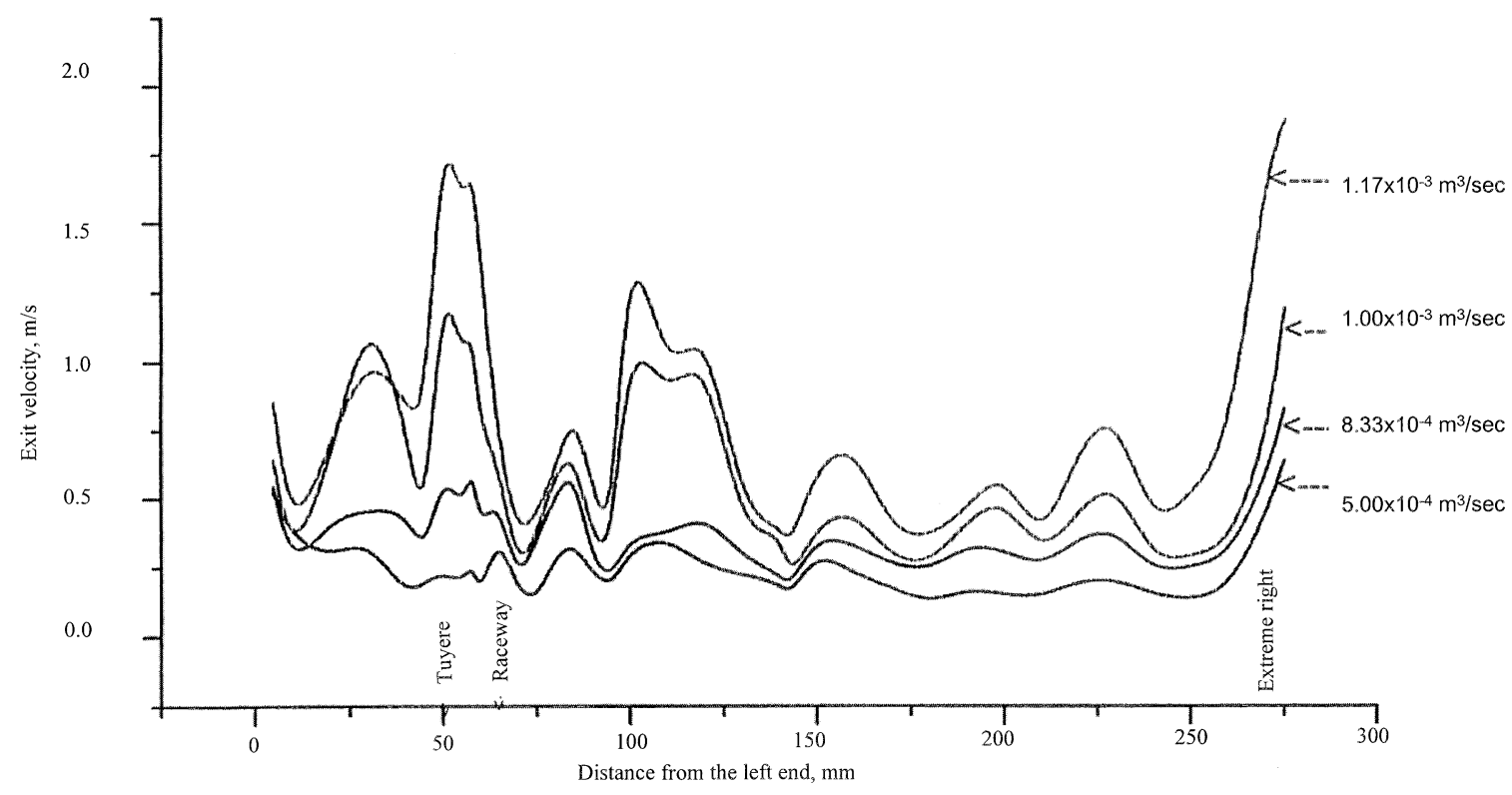

Fig. 12. Exit gas velocity profiles at the top of the bed for different gas flow rates. $d_{\mathrm{p}}=3.1 \mathrm{~mm}$ (polypropylene), $W=17 \mathrm{~mm}$, and $H=200 \mathrm{~mm}$.

ing in $\mathrm{m}, d_{\mathrm{p}}$ is the particle diameter in $\mathrm{m}, H_{\text {eff }}$ is the effective bed height in $\mathrm{m}, \mathrm{g}$ is gravitational constant and, $\rho_{\mathrm{s}}$ and $\rho_{\mathrm{g}}$ are the solid and gas densities in $\mathrm{kg} / \mathrm{m}^{3}$ respectively. $A$, $B, C$ and $D$ are constants.

Using the linear regression analysis of the experimental data, the constants $A, B, C$ and, $D$ were found for void for- mation and breaking conditions respectively.

Therefore, for void formation the correlations is

$$
\frac{V_{\mathrm{b}}^{2}}{g d_{\mathrm{t}}}=14.5\left(\frac{\rho_{\mathrm{s}}}{\rho_{\mathrm{g}}}\right)^{0.35}\left(\frac{H_{\mathrm{eff}}}{d_{\mathrm{t}}}\right)^{0.6}\left(\frac{d_{\mathrm{p}}}{d_{\mathrm{t}}}\right) \ldots
$$


In Fig. 13 the experimental data points are compared with this correlation. A good agreement was observed between the two.

Similarly for void/raceway breaking, the correlation is

$$
\frac{V_{\mathrm{b}}^{2}}{g d_{\mathrm{t}}}=12.5\left(\frac{\rho_{\mathrm{s}}}{\rho_{\mathrm{g}}}\right)^{0.6}\left(\frac{H_{\mathrm{eff}}}{d_{\mathrm{t}}}\right)^{0.7}\left(\frac{d_{\mathrm{p}}}{d_{\mathrm{t}}}\right)
$$

In Fig. 14 the experimental data points are compared with this correlation. A good agreement was observed between the two. There are no published data available to compare

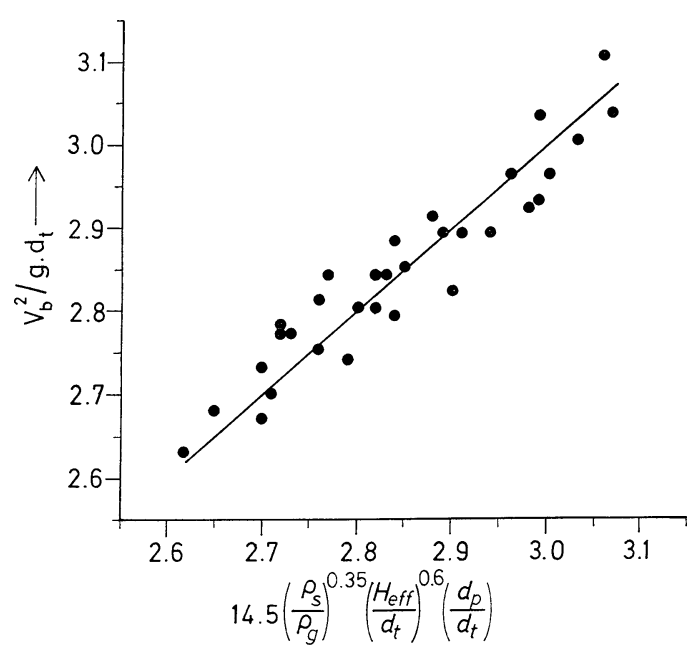

Fig. 13. Correlation vs. experimental results for void formation condition.

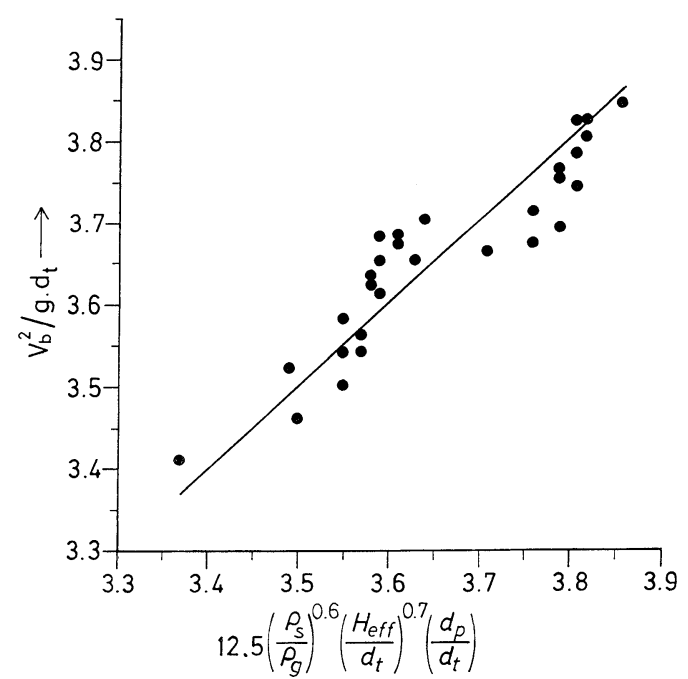

Fig. 14. Correlation vs. experimental results for breaking condition. the results with the above mentioned correlations.

\section{Conclusions}

It has been found that particle size, shape and materials properties have a wide influence on the void formation and void breaking. As the particle size, bed height and density of the particle increases the critical velocity for the both void formation and breaking increases. Velocity measurement in the packed bed shows that exit velocity is almost double at the top of the raceway and near the wall in comparison the other part of the bed. It is also observed that the model width influences the critical velocity in both the cases. Pressure measurement shows the evidence of formation of void and breaking of void by distinct change in its value. The effective bed height is a function of system dimensions and frictional properties of the material. Modified Janssen's equation may be applied to quantify the effect of these factors on the effective bed height.

\section{REFERENCES}

1) K. A. Pilcher and J. Bridgwater: Chem. Eng. Sci., 45 (1990), 2535.

2) F. J. Doyale III, R. Jackson and J. C. Ginestra: Chem. Eng. Sci., 41 (1986), 1485.

3) B. H. Xu, A. B. Yu, S. J. Chew and P. Zulli: Powder Technol., 109 (2000), 13.

4) G. S. Gupta, J. D. Litster, V .R. Rudolph and E. T. White: ISIJ Int., 33 (1996), 32.

5) ISIJ: Blast Furnace Phenomena and Modelling, Elsevier Applied Sci., London, (1987), 376.

6) J. Szekely and J. Poveromo: Metall. Trans., 6B (1975), 119.

7) P. J. Flint and J. M. Burgess: Metall Trans., 23B (1992), 267.

8) M. Hatano, M. Fukuda and M. Takeuchi: Tetsu-to-Hagané, 62 (1976), 25.

9) M. Nakamura, T. Sugiyama, T. Uno, Y. Hara and S. Kondo: Tetsu-toHagané, 63 (1977), 28.

10) J. B. Wagstaff and W. H. Holman: Trans. AIME, (1957), 370

11) J. F. MacDonald and J. Bridgwater: Chem. Eng. Sci., 52 (1997), 677.

12) T. Nishi, H. Haraguchi, Y. Miura, S. Sakurai, K. Ono and H. Kanoshima: Trans. Iron Steel Inst. Jpn., 22 (1982), 287.

13) P. Gupta: M.Sc.(Engg.) Thesis, Indian Institute of Science, Bangalore, (1998).

14) G. S. Gupta, J. D. Litster, V. R. Rudolph and E. T. White: CRL Report No. 67/03, BHP Steel, Newcastle, Australia, (1993).

15) H. A. Janssen: Z. ver. Dt. Ing., 39 (1895), 1045.

16) G. S. S. R. K. Sastry: M.Sc. (Engg) Thesis, Indian Institute of Science, Bangalore, (2000).

17) T. W. Lambe: Soil Testing for Engineers, 5th Ed., Wiley Eastern Ltd., London, (1993), 88.

18) R. F. Benenati and C. B. Brosilow: AIChE J., 8 (1962), 359.

19) J. F. Elliott, R. A. Bachanan and J. B. Wagstaff: Trans. AIME, 194 (1952), 709.

20) J. B. Wagstaff: Trnas. AIME, 197 (1953), 895.

21) J. F. Davidson and D. Harrison: Fluidization, Academic Press, London, (1971), 15. 